\title{
A ludicidade como estratégia pedagógica
}

\section{The ludicity as a pedagogical strategy}

\author{
Thays Votto, Mauren Porciúncula \\ Universidade Federal do Rio Grande
}

\begin{abstract}
Resumo
O objetivo desse artigo é analisar a ludicidade presente ou emergente nas estratégias pedagógicas utilizadas por professores dos anos iniciais da Educação Básica brasileira, bem como as concepções destes sobre esse fenômeno. A metodologia utilizada nesse estudo consiste em uma análise temática acerca das concepções de professoras sobre a ludicidade. A coleta de dados foi realizada por meio de entrevistas semiestruturadas, com quatro profissionais. A análise dos resultados revela que a maioria das profissionais não tem clareza da concepção epistemológica que subjaz a sua prática lúdica. Entretanto, reconhecem a presença da ludicidade através de jogos e brincadeiras, em sua prática.

Palavras-chave: Ludicidade, Psicologia do Desenvolvimento, Estratégias de Aprendizagem
\end{abstract}

\begin{abstract}
The aim of this study is to analyze the ludicity present or emerging on pedagogical strategies used by primary teachers of Brazilian basic education, as well as their conceptions about this phenomenon. The methodology used consists of a theme analysis about teachers conceptions on ludicity. As a data production tool, semi-structured interviews were conducted with four professionals. The data analysis shows the majority of professionals do not have clear in their minds the epistemological conception underlying their ludicity practice. However, they acknowledge the ludicity through plays and games in their practice.

Keywords: Ludicity, Developmental Psychology, Learning Strategies
\end{abstract}

\section{Introdução}

A ludicidade vem se constituindo como um fenômeno que pode ser desenvolvido em diversos ambientes, proporcionando diferentes experiências àqueles que as vivenciam, ao passo que os aspectos lúdicos estão sendo pesquisados na educação matemática (Muniz, 2016), na formação inicial do professor no curso de Letras (Santos \& Wanderley, 2016). Além de estar presente tanto no processo de alfabetização (Stabenow, 2011) quanto na educação em saúde, promovendo atividades de promoção à saúde bucal com atividades lúdicas (Nunes, 2011), e ainda observamos a contribuição das atividades lúdicas realizadas com crianças hospitalizadas (Moura, 2013), entre outras.

O fenômeno denominado ludicidade vem ganhando espaço na literatura, ao passo que diversos teóricos ocuparam-se por estudar esse termo, associando-o a diferentes enfoques, como socioculturais (Huizinga, 1971; Benjamin, 1984; Kishimoto, 1998, 2006; Brougère, 1998, 2002), que enfatizam jogo e brinquedo como elementos desenvolvidos a partir do contexto sociocultural do sujeito; educacional, dissertando sobre a Educação Lúdica a partir dos escritos de Almeida (1990), e conceituando o lúdico temos Luckesi $(2000,2002)$ e Dantas (2002).

Nessa perspectiva, concebemos assim como Brougère (2006), que o meio sociocultural em que vivemos é permeado por atividades lúdicas. Sendo assim, tais atividades constituem a nossa identidade a partir das interações sociais com nossos pares. O referido autor integra essas ideias ao afirmar que a socialização pressupõe uma apropriação cultural. Nesse contexto, Benjamin (1984) enfatiza que a partir do brincar e do manuseio dos brinquedos que estão em seu meio, a criança estabelece um diálogo simbólico entre ela e seu povo.

Dessa forma, a criança, assim como o adulto, se desenvolve imersa nessa cultura, dispondo dos elementos desta, para criar, brincar e realizar representações da sua realidade, constituindo assim, uma cultura lúdica. Compreendemos por cultura lúdica uma estrutura complexa e organizada, constituída de brincadeiras conhecidas e disponíveis, de costumes lúdicos, brincadeiras individuais, tradicionais ou geracionais, entre diversas atividades. (Brougère, 2006). Nessa perspectiva, cada contexto social constrói uma imagem de jogo conforme seus valores e modos de vida, que se expressa por meio da linguagem. (Brougère, 1998; Almeida, 1990).

Nesse contexto, Brougère (1998) apresenta diferentes níveis de significação para o termo jogo. O primeiro deles seria caracterizado pela ação dos seres que jogam, sendo uma atividade complexa. $\mathrm{O}$ segundo nível se refere ao jogo a partir de um sistema de regras. Durante a atividade lúdica, esses dois níveis se sobrepõem, tendo em vista que "quando o jogo se desenrola, há jogo no sentido da situação lúdica e presença de um jogo no sentido de sistema de regras". (p.15). O terceiro está relacionado ao objeto em si, podendo estar associado ao brinquedo.

Em busca de outras características do jogo, valemo-nos de escritos de Huizinga (1971) que concebe o jogo como uma atividade livre, conscientemente tomada como "não-séria" e exterior à vida habitual, mas ao mesmo 
tempo capaz de absorver o jogador de maneira intensa e total. "É uma atividade desligada de todo e qualquer interesse material, com a qual não se pode obter qualquer lucro, praticada dentro de limites espaciais e temporais próprios, segundo uma certa ordem e certas regras.”. (p. 13).

Além das características apresentadas acima, Huizinga (1971) e Kishimoto (1998) apresentam algumas reflexões acerca dos jogos. Uma delas é que, embora na maioria das situações de jogo predominem sentimentos de prazer, existem situações em que o desprazer é o elemento que caracteriza a situação lúdica. Nesse contexto, Vigotsky (2007) expõe que o prazer não pode ser visto como uma característica definidora do jogo, exemplificando que durante uma partida de um determinado jogo, este não será prazeroso para a criança se esta não estiver contente com o resultado.

A partir do exposto até aqui, compreendemos que a brincadeira, assim como o jogo, pode ser concebida como um conjunto de linguagem, ao passo que ela "simboliza a relação pensamento-ação e sob, esse ponto, constitui provavelmente a matriz de toda a atividade linguística, ao tornar possível o uso da fala, do pensamento e da imaginação." (Almeida, 1990, p. 26).

Nessa perspectiva, torna-se interessante refletirmos sobre essa contribuição dos jogos e das brincadeiras a partir do ponto de vista educacional. Dito isso, segundo Kishimoto (2010), o brincar confere à criança o poder de tomar decisões, expressar sentimentos e valores e, portanto, conhecer a si mesma, aos outros e o mundo. Além de repetir ações prazerosas, de partilhar, expressar sua individualidade e identidade por meio de diferentes linguagens utilizando o corpo, os sentidos e os movimentos a fim de solucionar problemas e criar.

Dessa forma, o brincar e a ludicidade, em toda a sua complexidade, são elementos que podem estar atrelados à prática educativa. Enfim, sua importância se relaciona com a cultura da infância, que coloca a brincadeira como ferramenta para a criança se expressar, aprender e se desenvolver. (Kishimoto, 2010).

A relação entre o brincar por meio do jogo e educação, acarreta uma série de questionamentos e indagações. A fim de trazer subsídios para essa discussão, vamos realizar um breve histórico dessa relação. O jogo educativo surgiu no século XVI, ganhando visibilidade com a Companhia de Jesus, que concebia a utilização do jogo como recurso auxiliar do ensino, visando à aquisição de conhecimentos. (Kishimoto, 1998). Nesse sentido, Brougère (1998), enfatiza que antes da Revolução Francesa, o jogo era considerado como uma possibilidade na educação sob três pontos de vista. $\mathrm{O}$ primeiro como recreação ou relaxamento, sendo indispensável ao esforço em geral, físico ou mental. O segundo, concebe ao jogo um caráter de artifício pedagógico, introduzindo-o por meio de exercícios escolares. Por fim, outro viés do jogo seria como uma oportunidade de exercitar o corpo, na escola, através de jogos na Educação Física.

Embora as primeiras manifestações do jogo na educação tenham sido datadas ainda no século XVI, foi somente no século XIX, com o término da Revolução Francesa - que possibilitou inovações pedagógicas -, que a utilização do jogo, principalmente com a teoria de Froebel, ganha reconhecimento. O referido autor atribuí ao jogo, entendido como objeto e ação de brincar, às características de liberdade e espontaneidade, ainda que vistos como recursos auxiliares à aquisição de conhecimento, concebidos como um meio de instrução. (Kishimoto, 1998).

Embora Foebel tenha uma visão inatista, de que o professor por meio dos jogos deve ser um intermediário entre os dons da criança e o mundo exterior, sendo os jogos um meio de tal exteriorização. Compreendemos que foi a partir dessas concepções que se começou a pensar no viés educativo dos jogos. (Brougère, 1998).

Kishimoto (1998) nos indaga sobre se há diferença entre o jogo e o material pedagógico, se o jogo educativo empregado em sala de aula seria realmente jogo, se o jogo tem um fim em si mesmo ou é um meio para alcançar um objetivo. A fim de clarificar essas questões, a autora faz algumas diferenciações, começando com o manuseio de brinquedos durante uma brincadeira. $\mathrm{O}$ brinquedo tem grande potencial para criar momentos lúdicos, de livre exploração, prevalecendo momentos de incerteza quanto à ação de brincar e não se buscam resultados. Entretanto, se utilizarmos os mesmos objetos como um suporte à prática docente, buscando dessa forma, resultados em relação à aprendizagem de determinada habilidade ou conceito, esse objeto perde sua função lúdica e transforma-se em material pedagógico. (Kishimoto, 1998).

Ainda segundo a referida autora, se concebermos que a escola tem objetivos a cumprir e o aluno tem a tarefa de adquirir conhecimentos e habilidades, quaisquer atividades realizadas por ele, no âmbito escolar, visam sempre a um resultado. Dessa forma, a utilização de um jogo nesse contexto, necessariamente se transforma em um meio para a realização daqueles objetivos. (Kishimoto 1998). Nesse sentido, o jogo, "entendido como ação livre, tendo um fim em si mesmo, iniciado e mantido pelos alunos, pelo simples prazer de jogar, não encontraria lugar na escola”. (p. 14). Tais indagações são profundamente discutidas por profissionais dá área e, segundo a autora supracitada, apontam que a partir delas, estabeleceu-se uma nova dimensão do jogo, o jogo educativo.

$\mathrm{Na}$ contemporaneidade, percebemos que existe uma preocupação em conciliar a liberdade e espontaneidade próprias dos jogos, com a orientação para um determinado fim, oriunda da prática pedagógica, visando superar a concepção de jogo na educação em seus primórdios (Kishimoto, 1998) - entendido como recurso auxiliar à aquisição do conhecimento. Indo ao encontro de tal preocupação, Brougère (1998) reconhece a importância do jogo no âmbito educacional, salientando que as características desse não devem ser esquecidas por ele encontrar-se nesse ambiente. Dessa forma, segundo o autor, a escola deve preocupar-se com todo o contexto para favorecer o brincar das crianças. Sendo assim, o educador deve assumir uma postura de mediador, sendo capaz de construir um ambiente também propício ao brincar.

De acordo com esse entendimento, Kishimoto (1998) apresenta duas funções do jogo educativo. A função 
lúdica, compreendida como aquela que propicia prazer, diversão, alegria e até mesmo desprazer, sendo voluntária. Por outro lado, a função educativa consiste em um jogo que ensina um determinado conteúdo que complete o indivíduo em seu saber. A educação por meio dos jogos busca um equilíbrio entre as duas funções do jogo educativo. Senão, pode haver um desequilíbrio, em que "não há mais ensino, há apenas jogo, quando a função lúdica predomina, o contrário, quando a função educativa elimina todo o hedonismo, resta apenas ensino". (p. 19). A partir do exposto até aqui, compreendemos que atrelar os aspectos lúdicos à educação seria uma oportunidade de tornar a aprendizagem agradável, prazerosa e que confira significado às atividades que a ela estão ligadas. Nesse sentido, a próxima sessão disserta sobre a educação lúdica.

\section{Educação Lúdica}

A expressão Educação Lúdica, segundo Almeida (1990), consiste num modelo educacional em que a ludicidade direciona as decisões e ações de caráter pedagógico. De acordo com o referido autor, está distante da concepção ingênua de passatempo ou diversão superficial. Ela é uma ação inerente a todos os seres humanos, desde a criança até a vida adulta, e aparece sempre como uma forma transacional em direção a algum conhecimento. (p. 13). Nesse contexto, a educação lúdica concebe a busca por conhecimento como uma atividade séria. Como tal, exige do estudante uma ação ativa, indagadora, reflexiva, além de criativa e socializadora. Essas relações constituem a essência da psicogenética da educação lúdica (Almeida, 1990). Dessa forma, opõe-se à passividade, submissão e alienação referentes à pedagogia dominadora enfatizada pela Educação Bancária de Freire (1981).

Imersos na discussão sobre a ludicidade, jogos, brincadeiras e uma educação lúdica, torna-se importante discorrer sobre o conceito de lúdico. O que determina uma atividade como lúdica ou não lúdica? No Brasil, segundo os dicionários, o conceito de ludicidade refere-se ao Ludismo que, por sua vez, quer dizer qualidade ou caráter de lúdico, e no que tange ao lúdico, ele está intimamente relacionado a divertimento, citando jogos e brinquedos, caracterizando o lúdico como qualquer atividade que possibilita distração. (Ferreira, 2010). Por outro lado, Brougère (1998) preconiza que a atividade lúdica pode dizer respeito a um reconhecimento objetivo a partir da observação externa ou ainda ao sentimento pessoal que cada indivíduo pode ter em certas circunstâncias ao participar de determinas atividades. Indo ao encontro dessa premissa, Luckesi (2000, 2002) confere à atividade lúdica como sendo aquela que propicia a plenitude da experiência. Dessa forma, a ludicidade é ação, construção e movimento que possibilita ao sujeito um estado de plenitude, prazer e alegria, sendo um fenômeno interno do sujeito, que possui manifestações no exterior. (Luckesi, 2002).

Por conseguinte, podemos conceber o ser humano em sua totalidade, dotado de expressão racional, mas também de dimensões lúdicas. Para tanto, torna-se necessário refletirmos sobre a ludicidade emergente nas relações humanas, estando associada não apenas à presença das brincadeiras ou jogos, mas também a um sentimento de atitude do sujeito, criança ou adulto, envolvido numa ação. Nessa perspectiva, tanto o brincar, o jogar e o agir ludicamente, exigem uma entrega total do ser humano, envolvendo na atividade lúdica, tanto o corpo quanto a mente. (Luckesi, 2000, 2002).

Dantas (2002) elucida que o termo lúdico abrange dois polos, sendo o primeiro caracterizado como uma atividade individual e livre, e o segundo, como coletiva e regrada. A autora refere que na teoria walloniana, o mundo infantil é sinônimo de lúdico. Sendo assim, toda atividade emergente é lúdica quando se exerce por si mesma, antes de poder integrar-se às atividades mais complexas dotadas de intencionalidade. Nessa concepção, existe uma marca dialética que preconiza um estado atual das coisas e um estado futuro, concebendo que a atividade regrada de hoje teve origem em uma atividade lúdica, livre e sem intencionalidade. (Dantas, 2002).

Nesse contexto, existem diversos saberes que são imprescindíveis à prática pedagógica como elucida Tardif (2006). Concebemos que a constituição do saber lúdico se apresenta como um dos saberes fundamentais à docência. Sendo assim, faz-se necessário o estudo deste durante a formação inicial e continuada dos educadores (Silva, 2014) a fïm de oportunizar uma (re)significação da prática pedagógica, buscando estratégias que favoreçam o processo de mediação do conhecimento para atender as necessidades que são demandadas nas escolas atualmente. (Silva \& Teixeira, 2016). Dessa forma, a ludicidade passa a ser percebida como um dos saberes docentes, garantindo espaço junto aos saberes específicos e pedagógicos. (Silva, 2014). A partir dessa breve discussão acerca da ludicidade, compreendemos que este fenômeno está além do uso de jogos, brinquedos e brincadeiras, podendo estar presente nas mais diversas atividades, tais como dançar, conversar, escrever, ler, etc., estando imersas tanto no universo infantil quanto no adulto, propiciando diferentes sentimentos àqueles que as vivenciam. Nesse contexto, a próxima sessão apresenta os métodos e procedimentos que foram utilizados nesse artigo com o intuito de compreender as concepções de professoras da Educação Básica acerca da ludicidade.

\section{Método}

O presente artigo configura-se, quanto sua abordagem, por uma pesquisa qualitativa. Quanto aos objetivos, caracteriza-se como uma pesquisa descritiva, cuja preocupação é descrever determinado fenômeno, tendo como objetivo estudar as características de um grupo; levantar opiniões, crenças e atitudes de uma determinada população. (Gil, 2002; Minayo, 2008; Lira, 2014). No que tange à análise dos dados coletados por meio de entrevistas, nos valemos de Minayo (2008).

\section{Participantes}

Participaram desse estudo, quatro professoras que lecionam nos Anos Iniciais da Educação Básica da rede pública brasileira. As participantes estão caracterizadas como P1, P2, P3 e P4. 


\section{Instrumentos}

O delineamento metodológico dessa pesquisa foi empregado mediante a realização de entrevistas semiestruturadas, que foram gravas e posteriormente transcritas, combinando perguntas abertas e fechadas que, de acordo com Minayo (2008), possibilita ao entrevistado discorrer sobre determinado assunto sem se prender à indagação formulada. As perguntas que fizeram parte das entrevistas foram: "O que é a ludicidade para você?", "O que caracteriza uma atividade como lúdica?” e "Um sinônimo para lúdico".

\section{Discussão dos resultados}

A presente análise foi realizada por meio da leitura e releitura do conteúdo das entrevistas transcritas, a fim de encontrar as principais temáticas que se destacaram no discurso e relacioná-las com as teorias elencadas nas primeiras sessões desse artigo. Dessa forma, agrupamos os discursos que se assemelhavam em alguns aspectos, sendo eles: caracterização da atividade lúdica; as dificuldades em introduzir as atividades lúdicas na sala de aula; importância da ludicidade; sentimentos dos alunos frente às atividades lúdicas; sinônimos para lúdico. A seguir, dissertaremos sobre de que forma as professoras que compõe essa pesquisa caracterizam uma atividade como lúdica.

De modo geral, emergem do discurso das entrevistas que as atividades lúdicas são caracterizadas por brincadeiras que façam as crianças refletirem e são capazes de proporcionar a socialização e, sobretudo, que elas gostem. Entretanto, uma das professoras entrevistadas mencionou que "a atividade lúdica tem que ter o brinquedo, o jogo, o jogo pedagógico e também o esquema do jogo corporal, depende do que tu está trabalhando, vai trabalhar a questão do corpo ai tu trabalha dança, a linguagem". (P1). A partir desse trecho, percebemos que, para além de compreender a ludicidade como centrada em jogos e brincadeiras, a professora tem consciência de que ela está presente em diversas atividades, como a dança e a expressão corporal, que pode ser moldada de acordo com o que se pretende trabalhar, sendo capaz de desenvolver diferentes tipos de linguagem. Sob esse ponto de vista, Brougère (1998) e Almeida (1990) enfatizam que, através das atividades lúdicas, a criança expressa seus valores e estilos de vida por meio da linguagem.

Quando a professora elenca uma série de atividades que podem ser consideradas como lúdicas, diz ainda que por meio da representação corporal "a dramatização, é o brincar com o corpo, é descontrair, [...] pra trabalhar a socialização, afetividade, e nisso aí a gente está trabalhando a linguagem, a fala, a diversidade das palavras, o tema trabalhado, então é importante." Este discurso mostra a variabilidade das atividades que podem ser consideradas como lúdicas. Nesse contexto, Luckesi (2000) apresenta uma série de exemplos de atividades que podem ser consideradas como lúdicas, como uma roda de conversa e a escrita de um livro, além de dançar, como exemplifica a entrevistada.

Outro trecho que se refere à caracterização de uma atividade lúdica que se destacou, foi "é se divertir com aquilo que está fazendo, não importa se aquilo teria uma intenção um pouco mais séria, mais pode ser lúdico e ao mesmo tempo ensinar" (P4). Tal pensamento vai ao encontro do que expõe Brougère (1998), quando ressalta que as características que remetem ao prazer, a alegrias inerentes ao jogo, não devem ser esquecidas por ele encontrar-se no âmbito educacional.

A próxima temática a ser analisada se apresenta de certa forma controversa, pois na medida em que as professoras caracterizam as atividades lúdicas como atividades importantes a serem desenvolvidas na escola, como se mostra nos discursos "é necessário, porque eles são crianças, e essa idade brincando se aprende bem melhor". (P1) e "talvez seja uma coisa que eles absorvam mais, porque traz uma coisa que eles gostam junto com o conteúdo, fica na memória quando a gente trás o lúdico junto". (P2). As mesmas apresentam algumas dificuldades ao inseri-las, referentes à desacomodação que uma atividade lúdica provoca. Além disso, relatam uma série de conteúdos que precisam ser passados aos alunos, que podem dificultar esse processo, em suas palavras “é muito corrido para nós também, porque a gente tem várias etapas pra ser vencidas, os dias passam muito rápidos, as turmas são muito cheias" $(\mathrm{P} 1)$ e ainda "o professor às vezes tem a dificuldade, porque tumultua a aula". (P2).

Contudo, mesmo com as dificuldades mencionadas acima, as professoras relatam que desenvolvem atividades lúdicas em sala de aula. Nessa perspectiva, uma das professoras não tinha consciência de que uma das suas atividades poderia ser interpretada como lúdica pelos seus alunos. Relatando que construíram um gráfico coletivo em que as informações foram coletadas por meio de pesquisa, enfatiza que eles gostaram muito da atividade, que foi visível o sentimento de alegria e empolgação nos alunos. Nesse viés, Luckesi (2000) enfatiza que, o que caracteriza uma atividade como lúdica, é a experiência interna do sujeito, que pode ter manifestações no exterior, ou seja, torna-se perceptível ao professor. Contudo, se a atividade foi de fato lúdica, somente o sujeito que a vivenciou poderá dizer. Dessa forma, podemos referir somente que determinadas atividades são potencialmente lúdicas, tendo em vista que são as experiências e os sentimentos dos sujeitos que determinarão uma atividade como lúdica.

Essas reflexões nos levam à próxima temática analisada: o sentimento dos alunos frente às atividades denominadas como lúdicas pelas professoras, expresso nos seguintes trechos "Eles ficam bem motivados" (P1), "eles adoram" (P4) e promovem "curiosidade, criatividade" (P2). Referente aos sinônimos para o lúdico empregados pelas entrevistadas, três delas responderem "Brincadeira", e uma delas disse "alegria", retomando aos escritos de Luckesi (2000) quando menciona que o prazer e a alegria estão imbricados nas atividades lúdicas.

Com base no exposto na análise acima, emergem do discurso das entrevistadas temáticas em comum, tais como o que caracteriza uma atividade como lúdica como sendo os sentimentos de prazer, alegria e motivação. Outra temática que surgiu diz respeito às dificuldades em inseri-las no âmbito educacional, ao passo que demonstram a importância desse fenômeno nesse espaço 
de formação. Além desses elementos, foram mencionados ainda, sentimentos dos alunos em relação às atividades compreendidas como lúdicas e a descrição de algumas delas, bem como a relação entre os sinônimos atribuídos para o lúdico.

\section{Considerações finais}

A partir do exposto nesse artigo, compreendemos que a ludicidade não pode ser definida a partir de um conceito imutável. Sendo assim, ela possui várias dimensões que possibilitam uma compreensão mais ampla desse fenômeno. Dessa forma, pode variar de acordo com a cultura e realidade sociocultural em que o sujeito está inserido. Além do que, a caracterização das atividades lúdicas vai muito além da sua representação em jogos, brinquedos e brincadeiras, podendo ser compreendida como um fenômeno que pode ser desenvolvido em diversos ambientes.

Partindo do pressuposto de que a ludicidade é um fenômeno interno ao sujeito, que possui manifestações no exterior, enquanto educadores não podemos dizer que esta ou aquelas atividades são lúdicas. Nesse contexto, podemos apenas ressaltar que elas são potencialmente lúdicas, visto que, o que é lúdico para um sujeito pode não o ser para outro. Esse fato faz com que o professor em sua prática pedagógica precise conhecer os seus alunos, percebendo suas características e personalidades a fim de que possa possibilitar um ambiente propício ao desenvolvimento de atividades lúdicas.

Algumas dessas concepções foram percebidas nos discursos das entrevistadas. No entanto, a maioria das professoras não tem consciência das teorias que subjazem à sua prática lúdica. Apenas as descrevem como jogos e brincadeiras que propiciam prazer e alegria. Outrossim, percebemos que a ludicidade pode estar presente em suas práticas pedagógicas, possibilitando dessa forma, aos alunos uma educação potencialmente lúdica.

\section{Referências}

Almeida, P. (1990). Educação Lúdica: Técnicas e jogos pedagógicos. São Paulo: Loyola.

Benjamin, W. (1984). Reflexões: A criança, o brinquedo, a educação. São Paulo: Summus.

Brougère, G. (1998). Jogo e educação. Porto Alegre: Artes Médicas.

Brougère, G. (2006.). Brinquedo e cultura. São Paulo: Cortez.

Dantas S, H. (2002). Brincar e Trabalhar. In O brincar e suas teorias. Tizuko Morchida (Org.). São Paulo: Pioneira Thomson Learning.

Ferreira, A. (2010). Dicionário Aurélio da Língua Portuguesa. Curitiba: Positivo.

Freire, P. (1981). Ação Cultural para a liberdade. Rio de Janeiro, Paz e Terra.

Gil, A. (1992). Como elaborar projetos de Pesquisa. São Paulo: Atlas.

Huizinga, J. (1971). Homo Ludens. São Paulo, Perspectiva.

Kishimoto, T. (1998). O jogo e a Educação Infantil. São Paulo: Pioneira.
Kishimoto, T. (Org.). (2006). Jogo, brinquedo, brincadeira e a educação. São Paulo: Cortez.

Kishimoto, T. (2010). Brinquedos e Brincadeiras na Educação Infantil. In: I Seminário Nacional: Currículo Em Movimento, 2010. Belo Horizonte. Anais... Belo Horizonte: Ufmg.

Lira, B. (2014). O passo a passo do Trabalho Cientifico. Petrópolis: Vozes.

Luckesi, C. (2000). Educação, ludicidade e prevenção das neuroses futuras: uma proposta pedagógica a partir da Biossíntese. In Educação e Ludicidade, Coletânea Ludopedagogia, FACED/UFBA.

Luckesi, C. (2002). Ludicidade e atividades lúdicas: uma abordagem a partir da experiência interna. In Porto, B. S. (Org.). Ludicidade: o que é mesmo isso?. Salvador.

Minayo, M. (2008). O desafio do conhecimento: pesquisas qualitativas em saúde. São Paulo: Hucitec.

Moura, I. (2013). O lúdico no hospital: um estudo teórico sobre atividades com crianças. (Dissertação de Mestrado Profissional). Escola Politécnica de Saúde Joaquim Venâncio, Fundação Oswaldo Cruz. https://www.arca.fiocruz.br/handle/icict/8603

Muniz, C. (2016). Educação Lúdica da Matemática, educação matemática lúdica. In Silva, A. J. \& Teixeira, H. S. (Org.). Ludicidade, formação de professores e educação matemática em diálogo. (pp. 19-37). Curitiba: Appris.

Nunes, R. (2011). Utilização do lúdico como estratégia na promoção de saúde bucal. (Dissertação de Mestrado em Educação) Universidade de Fortaleza. Fortaleza. https://uolp.unifor.br/oul/ObraBdtdSiteTrazer.do?met hod=trazer\&ns $=$ true \&obraCodigo $=72103$

Santos, M. das D.; Wanderley, M. (2016.). A ludicidade na formação inicial de professor no curso de letras. In: Silva, A. J. N. da; Teixeira, H. S. (Org.). Ludicidade, formação de professores e educação matemática em diálogo. (pp. 80-94). Curitiba: Appris,

Silva, A. (2014). Formação Lúdica do futuro professor de matemática por meio do laboratório de ensino. (Dissertação de Mestrado). Universidade de Brasília. Brasília.http://repositorio.unb.br/bitstream/10482/166 11/1/2014_AmericoJuniorNunesdaSilva.pdf

Silva. A \& Teixeira, H. (Org). (2016). Ludicidade, formação de professores e educação matemática em diálogo. Curitiba: Appris.

Stabenow, F. (2011). Narrativas de Professoras Alfabetizadoras: O Lugar do Lúdico na Alfabetização. (Dissertação de Mestrado) Universidade Federal do Amazonas. Manaus: UFAM. http://tede.ufam.edu.br/handle/tede/3225\#preview-lin $\mathrm{k} 0$

Tardif, M. (2006). Saberes docentes e formação profissional. Petrópolis: Vozes.

Vigotsky, L. (2007). A formação social da mente: O desenvolvimento dos processos psicológicos superiores. São Paulo: Martins Fontes. 